\title{
FAKTOR-FAKTOR YANG MEMPENGARUHI KEPATUHAN WAJIB PAJAK DALAM MELAKUKAN PEMBAYARAN PPH 21 (Orang Pribadi pada Multi Level Marketing di Surabaya)
}

\author{
Yulia Setyarini \\ Universitas Widya Kartika \\ yulia@widyakartika.ac.id \\ Susan \\ Universitas Widya Kartika \\ Susanliem8@gmail.com
}

\begin{abstract}
Taxes are the main source of state revenue, one of which comes from an individual taxpayer. Taxes have a very important role to sustain development implementation and government spending. This study aims to determine the partial influence of the level of understanding of taxpayers, awareness, and tax sanctions on compliance with income taxpayer article 21 (individual taxpayer at multi level marketing in Surabaya). The research uses primary data by distributing questionnaires to individual taxpayers doing MLM work in Surabaya. The results of this study indicate that the understanding of the regulation does not partially affect taxpayer compliance because it has a significant level $>0.05$ this is because the tax regulations are constantly updated resulting in a lack of understanding of taxpayers. For awareness, as well as sanctions taxation partially affect taxpayer compliance because it has a significant level $<0.05$.
\end{abstract}

Keywords: Taxpayer Understanding, Awareness, Tax Sanction, MLM Distributor and Tax Compliance Income Taxpayer Article 21

\begin{abstract}
ABSTRAK
Pajak adalah sumber utama penerimaan negara, salah satunya berasal dari wajib pajak orang pribadi. Pajak memiliki peran yang sangat penting untuk mempertahankan implementasi pembangunan dan pengeluaran pemerintah. Penelitian ini bertujuan untuk mengetahui pengaruh parsial tingkat pemahaman wajib pajak, kesadaran, dan sanksi pajak terhadap kepatuhan wajib pajak melalui pajak penghasilan pasal 21 (wajib pajak orang pribadi pada multi level marketing di Surabaya). Penelitian ini menggunakan data primer dengan menyebarkan kuesioner kepada wajib pajak individu yang melakukan pekerjaan MLM di Surabaya. Hasil penelitian ini menunjukkan bahwa pemahaman peraturan secara parsial tidak mempengaruhi kepatuhan wajib pajak karena memiliki tingkat signifikan> 0,05 hal ini karena peraturan pajak terus menerus diperbarui mengakibatkan masyarakat yang tidak mengikuti perkembangan peraturan perpajakan tidak akan paham perpajakan. Kesadaran dan sanksi perpajakan secara parsial mempengaruhi kepatuhan wajib pajak karena memiliki tingkat signifikan $<0,05$.
\end{abstract}

Kata kunci: Pengertian Wajib Pajak, Kesadaran, Sanksi Pajak, Distributor MLM dan Penghasilan Kepatuhan Pajak. Pasal 21 


\section{PENDAHULUAN}

Sumber pendapatan suatu pemerintahan dapat berupa pajak, devisa dan laba dari BUMN. Direktorat Jenderal Pajak Kementerian Keuangan mengatakan bahwa Pajak merupakan sumber pernerimaan negara yang terutama dan yang paling aman. Sektor perpajakan memiliki peran sangat penting dalam menjamin keberlangsungan kehidupan bangsa kita, khususnya dalam mewujudkan kehidupan bangsa yang cerdas,sejahtera, adil, dan damai. Penerimaan negara yang berasal dari pajak pada tahun 2016 mencapai 74.6\% dari total pendapatan negara. Direktur Penyuluhan dan Pelayanan Hubungan Masyarakat Direktorat Jenderal Pajak (DJP), Hestu Yoga Saksama menyampaikan bahwa hampir $70 \%$ penerimaan negara bersumber dari pajak. Namun, rasio perpajakan Indonesia hanya $11 \%$ dan hal tersebut terbilang rendah,.Untuk itu diperlukan pemahaman sejak dini dan kesadaran dalam menunaikan kewajibannya sebagai pembayar pajak dan juga penikmat pajak sehingga rasio penerimaan pajak ke depan, bisa meningkat. (Media Indonesia).

Direktorat Jenderal Pajak (DJP) Kementerian Keuangan (Kemenkeu) menyatakan penerimaan pajak tahun 2017 sudah jauh lebih baik dibandingkan 2016. Pada Tahun 2017 pertumbuhan pendapatan negara melalui pajak naik signifikan. Sebagai contoh, pertumbuhan pajak penghasilan $(\mathrm{PPh})$ orang pribadi mampu tumbuh 44 persen, PPN sampai November tumbuh 15 persen, PPh badan 17 persen, $\mathrm{PPh} 21$ tumbuh 6 persen,". (www.liputan6.com).

Harian Tempo.CO, Jakarta pada tanggal 31 Desember 2016, Direktorat Jendral Pajak Kementerian Keuangan menyatakan penerimaan pajak menjelang akhir tahun 2016 sudah mendekati 82 persen dari target dalam APBN perubahan 2016, program tersebut mengarah pada semua lapisan masyarakat di Indonesia, termasuk pada komunitas hobi, olahraga, sosial dan juga organisasi profesi seperti dokter dan pengacara. Kemudian, perusahaan asuransi, Multi Level Marketing (MLM), dan direct selling (Penjualan Langsung).

Banyaknya peminat akan bisnis ini yang membuat bisnis Multi Level Marketing (MLM) berkembang dengan pesat di Indonesia. Bisnis ini dijadikan pemasukan tambahan bagi para pekerja kantoran, pegawai negeri, ibu rumah tangga bahkan mahasiswa untuk menambah penghasilannya. Hal ini dikarenakan penghasilan yang didapatkan kurang dibandingkan kebutuhan hidup yang semakin meningkat. Bisnis MLM ini merupakan bisnis yang modern dan fleksibel serta mudah dijalankan oleh setiap orang tanpa harus melihat latar belakangnya.

Rumusan masalah pada penelitian ini adalah apakah pemahaman, kesadaran serta sanksi perpajakan berpengaruh terhadap kepatuhan wajib pajak dalam melakukan pembayaran pph 21 Orang Pribadi yang berbisnis MLM di Surabaya. Tujuan penelitian ini adalah untuk membuktikan pengaruh pemahaman, kesadaran serta sanksi perpajakan terhadap kepatuhan wajib pajak dalam melakukan pembayaran pph 21 Orang Pribadi yang berbisnis MLM di Surabaya 


\section{LANDASAN TEORI}

\section{Pajak Multi Level Marketing (MLM)}

Berdasarkan Surat Edaran Dirjen Pajak Nomor SE-39/PJ.43/1999 tentang "Perlakuan Perpajakan atas Penghasilan sehubungan Kegiatan Multilevel Marketing" menjelaskan bahwa atas rabat merupakan penghasilan yang terutang dan harus dipotong Pajak Penghasilan Pasal 21. Atas penghasilan karena selisih antara harga distributor dengan harga yang dianjurkan oleh perusahaan Multilevel Marketing adalah merupakan penghasilan yang harus dilaporkan dalam SPT Tahunan PPh Orang Pribadi. Yang merupakan subyek pajak adalah seluruh Member/Anggota/Distributor yang telah bergabung secara resmi dan terdaftar pada sebuah perusahaan MLM, dan bukan karyawan tetap ataupun menerima penghasilan tetap dari perusahaan tersebut, sedangkan Obyek pajak adalah seluruh penghasilan yang diperoleh sebagai member dari perusahaan MLM. Penghasilan sebagai member perusahaan MLM terbagi atas 2 kelompok, yaitu hasil dari penjualan (selling product) dan hasil dari pengembangan jaringan atau insentif lainnya (networking).

Menurut MLM Leaders (2007:20), Multi Level Marketing (MLM) adalah metode pendistribusian barang atau jasa dengan sistem penjualan langsung melalui program pemasaran berbentuk jaringan. Dimana para distributornya akan mendapatkan pendapatan dari penjualan langsung yang dilakukan sendiri dan pendapatan dari total omzet jaringan atau kelompok dari organisasi yang telah dibangunnya. Dikatakan Multi Level Marketing (MLM) karena organisasi distributor penjualnya berjenjang banyak.

\section{Hipotesis}

Pemahaman Peraturan Perpajakan dan kepatuhan wajib pajak Orang Pribadi Tingkat pemahaman wajib pajak berpengaruh signifikan secara parsial terhadap tingkat kepatuhan wajib pajak, hal ini berarti semakin tinggi tingkat pemahaman, maka kepatuhan wajib pajak akan tercapai (Puspitasari,2015). Dengan tingkat pemahaman yang baik seseorang akan dapat melaksanakan sesuatu dengan baik pula. Tingkat pemahaman wajib pajak merupakan suatu proses dari peningkatan pengetahuan wajib pajak terhadap segala peraturan perpajakan yang berlaku di Indonesia. Apabila peraturan perpajakan dibentuk dengan sederhana akan mempermudah wajib pajak dalam mengimplementasikan kewajiban perpajakannya yang berlaku di Indonesia. Apabila peraturan perpajakan dibentuk dengan sederhana akan mempermudah wajib pajak dalam mengimplementasikan kewajiban perpajakannya. Berdasarkan uraian diatas, maka dirumuskan hipotesis sebagai berikut:

H1: Pemahaman Peraturan Perpajakan berpengaruh terhadap kepatuhan WP Orang Pribadi

\section{Kesadaran Perpajakan dan kepatuhan wajib pajak Orang Pribadi}

Kesadaran membayar pajak di Indoensia relatif rendah dibandingkan dengan negara-negara Jepang dan Australia, padahal tariff pajak di negara tersebut lebih besar dibandingkan dengan tariff pajak di Indonesia. Menurut Ditjen Pajak (2015), warga Jepang dan Australia sangat 
bangga ketika mereka membayar pajak karena hal tersebut merupakan wujud kecintaan mereka kepada negaranya. Soemitro $(1988 ; 80)$ menambahkan bahwa kesadaran pajak harus diikuti dengan rasa tertarik untuk membayar pajak (tax madidness), dan akhirnya melahirkan sikap disiplin dalam membayar pajak (tax discipline). Saraswati,dkk (2018), Muliari dan Nugroho (2006) semakin tinggi tingkat kesadaran wajib pajak maka pamahaman dan pelaksanaan kewajiban perpajakan semakin baik sehingga dapat meningkatkan kepatuhan. Berdasarkan uraian diatas, maka dirumuskan hipotesis sebagai berikut:

$\mathrm{H}_{2}$ : Terdapat pengaruh kesadaran perpajakan secara parsial terhadap kepatuhan wajib pajak orang pribadi yang melakukan pekerjaan MLM.

\section{Sangsi Perpajakan dan kepatuhan wajib pajak orang Pribadi}

Sanksi perpajakan merupakan jaminan bahwa ketentuan peraturan perundang-undangan perpajakan (norma perpajakan) akan dituruti/ditaati/dipatuhi. Atau bisa dengan kata lain sanksi perpajakan merupakan alat pencegah (preventif) agar wajib pajak tidak melanggar norma perpajakan (Mardiasmo, 2011:59). Pengertian kepatuhan Wajib Pajak menurut Nurmantu yang dikutip dalam Rahayu (2010:138), menyatakan bahwa kepatuhan perpajakan dapat didefinisikan sebagai suatu keadaan dimana Wajib Pajak memenuhi semua kewajiban perpajakan dan melaksanakan hak perpajakannya. Berdasarkan uraian diatas, maka dirumuskan hipotesis sebagai berikut:

$\mathrm{H}_{3}$ : Terdapat pengaruh sanksi pajak secara parsial terhadap kepatuhan wajib pajak orang pribadi yang melakukan pekerjaan MLM.

\section{METODE PENELITIAN}

Metode peneltian ini menggunakan pendekatan kuantitatif yang diolah dengan menggunakan software SPSS. Sumber data yang digunakan dalam penelitian ini adalah data primer. Data primer adalah data yang diperoleh langsung dari sumbernya, diamati dan dicatat untuk pertama kalinya. Teknik penentuan sampel dalam penelitian ini adalah purposive sampling dan snowball sampling. Pengumpulan data melalui kuisioner yang dibagikan sebanyak 100 dan yang dapat diolah sebanyak 72 kuisioner. Berikut ini penjelasan profil responden.

Tabel 1 Profil Responden

\begin{tabular}{|c|l|c|c|}
\hline No & \multicolumn{1}{|c|}{ Keterangan } & Responden & Persentase \\
\hline 1. & Jumlah kuisioner yang disebar & 100 & $100 \%$ \\
\hline 2. & Jumlah kuisioner yang tidak kembali & 26 & $26 \%$ \\
\hline 3. & Jumlah kuisioner yang tidak dapat diolah & 2 & $2 \%$ \\
\hline 4. & Jumlah kuisioner yang dapat diolah & 72 & $72 \%$ \\
\hline
\end{tabular}


Dari kuisioner disebarkan berjumlah 100 lembar dan jumlah yang kembali adalah sebanyak 74 lembar atau $74 \%$ dan yang tidak kembali adalah 26 lembar atau $26 \%$. Kuisioner yang dapat diolah berjumlah 72 lembar atau $72 \%$, sedangkan yang tidak dapat diolah karena pendapatannya dibawah Pendapatan Tidak Kena Pajak (PTKP) dan status pekerjaan sebagai ibu rumah tangga berjumlah 2 lembar atau $2 \%$.

\section{PEMBAHASAN}

Suatu kuisioner dikatakan valid jika pertanyaan dalam kuisioner mampu mengungkapkan sesuatu yang diukur pada kuisioner tersebut. Pengujian ini dilakukan dengan menggunakan Pearson Corelation, dari hasil penelitian ini menunjukan tidak terdapat koefisien korelasi dimana tingkat signifikansinya $<0,05$ sehingga data kuisioner dikatakan valid. Selain itu uji reliabilitas dilakukan untuk menilai konsistensinya dari instrument penelitian ini, hasil penelitian ini memiliki nilai Cronbach Alpha $>0,6$ sehingga data kuisioner dikatakan reliabel.

Pengujian multikolonieritas dilakukan untuk menguji apakah pada model regresi ditemukan adanya korelasi antar variabel independen. Dengan demikian, dapat disimpulkan bahwa persamaan regresi tidak terdapat problem multikolinearitas. Uji Multikolinearitas ini dapat dilihat pada tabel 2 sebagai berikut:

Tabel 2 Hasil Uji Multikolinearitas

\begin{tabular}{|c|l|c|c|}
\hline No & \multicolumn{1}{|c|}{ Variabel Bebas } & Tolerance & VIF \\
\hline 1 & Pemahaman Peraturan Pajak & 0,947 & 1,056 \\
\hline 2 & Kesadaran Wajib Pajak & 0,946 & 1,057 \\
\hline 3 & Sanksi perpajakan & 0,987 & 1,013 \\
\hline
\end{tabular}

Pengujian heteroskedastisitas dilakukan untuk menguji apakah dalam sebuah model regresi, terjadi ketidaksamaan varians dari residual dari satu pengamatan ke pengamatan yang lain. Dalam penelitian ini tidak terjadi heteroskedastisitas karena grafik Scatter plot yang menunjukkan titik-titik menyebar secara acak dan tidak membentuk pola tertentu serta tersebar diatas dan dibawah angka 0 (nol) pada sumbu Y. Uji Heteroskedastisitas ini dapat dilihat pada gambar 1 sebagai berikut: 


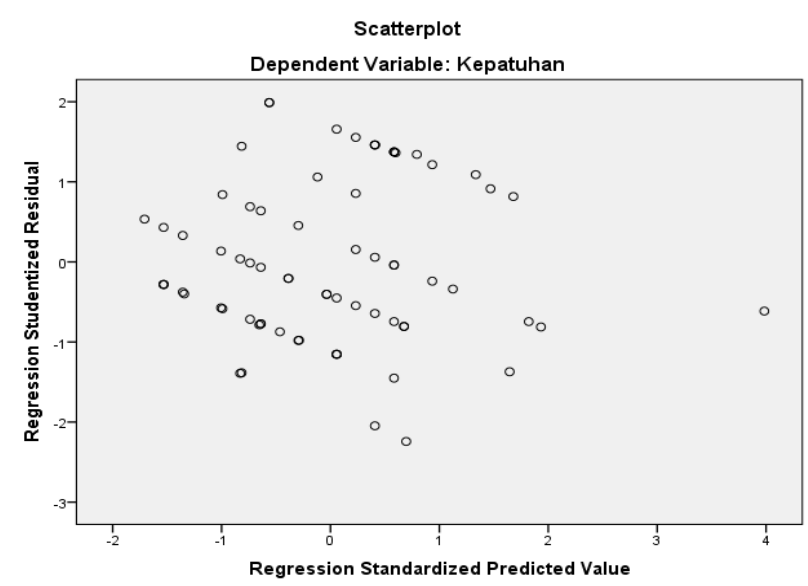

Gambar 1 Uji Heteroskedastisitas

Uji normalitas dalam penelitian ini menggunakan metode grafik normal Probability Plot. Jika residual berasal dari distribusi normal, maka nilai-nilai sebaran data akan terletak disekitar garis lurus, dengan demikian dapat dikatakan bahwa penyebaran normalitas terpenuhi. Uji Normalitas data dapat dilihat pada gambar 2 sebagai berikut:

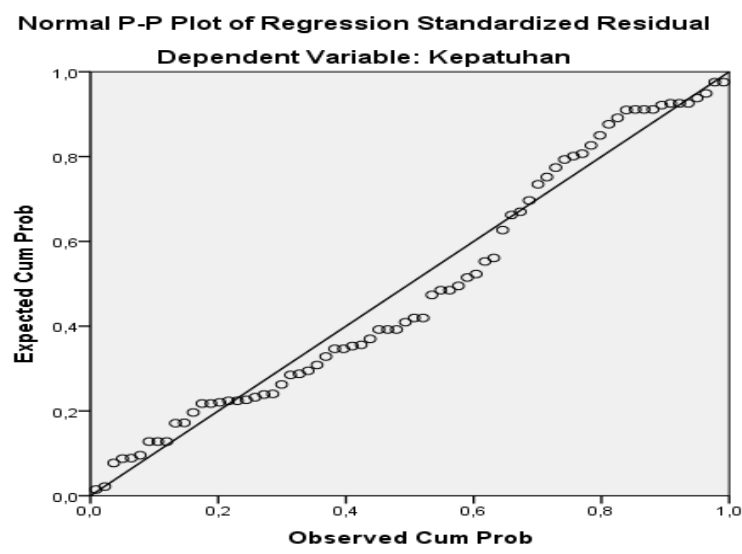

Gambar 2 Uji Normalitas Data

Uji hipotesis dalam penelitian ini dilakukan dengan menggunakan analisis regresi linear berganda, koefisien determinasi $\left(\mathrm{R}^{2}\right)$ dan uji hipotesis t. Hasil persamaan analisis regresi linear berganda yang dihasilkan sebagai berikut:

$$
Y=0,530-0,138 X_{1}+0,623 X_{2}+0,424 X_{3}+e
$$

Dari persamaan regresi di atas dapat diperoleh penjelasan bahwa nilai konstanta sebagai variabel bebas atau $\mathrm{X}_{1}, \mathrm{X}_{2}, \mathrm{X}_{3}=0$, maka efisiensi kepatuhan wajib pajak sebesar 0,530. Nilai koefisien regresi variabel pemahaman peraturan $\left(X_{1}\right)$ sebesar -0,138 dapat diartikan bahwa jika variabel pemahaman peraturan meningkat $1 \%$ maka 
kepatuhan wajib pajak (Y) mengalami penurunan sebesar 0,138. Nilai koefisiensi regresi variabel kesadaran wajib pajak $\left(\mathrm{X}_{2}\right)$ sebesar 0,623 dapat diartikan bahwa jika variabel kesadaran wajib pajak meningkat $1 \%$ maka kepatuhan wajib pajak (Y) mengalami peningkatan sebesar 0,623. Nilai koefisiensi regresi variabel sanksi perpajakan $\left(\mathrm{X}_{3}\right)$ sebesar 0,424 dapat diartikan bahwa jika variabel sanksi perpajakan meningkat $1 \%$ maka kepatuhan wajib pajak (Y) mengalami peningkatan sebesar 0,424.

Uji Koefisien determinasi $\left(\mathrm{R}^{2}\right)$ pada penelitian ini, jika angka $\mathrm{R}$ square memiliki nilai diatas 0,5 maka korelasi atau hubungan antara variabel independen dengan variabel dependen adalah kuat. Hasil Uji Koefisien determinasi $\left(\mathrm{R}^{2}\right)$ dapat dilihat pada tabel 3. Dimana $\mathrm{R}^{2}$ adalah 0,236 dimana pada penelitian ini sebesar 76,4 dipenagruhi oleh factor lain.

Tabel 3 Nilai Koefisien Determinasi $\left(\mathbf{R}^{2}\right)$

\begin{tabular}{|c|r|r|r|r|}
\hline Model & \multicolumn{1}{|c|}{$\mathrm{R}$} & R Square & \multicolumn{1}{c|}{$\begin{array}{c}\text { Adjusted R } \\
\text { Square }\end{array}$} & $\begin{array}{c}\text { Std. Error of } \\
\text { the Estimate }\end{array}$ \\
\hline 1 &, $485^{\mathrm{a}}$ &, 236 &, 202 & 1,443 \\
\hline
\end{tabular}

a. Predictors: (Constant), Sanksi, Pemahaman, Kesadaran

Uji t dapat digunakan untuk mengetahui signifikan tidaknya pengaruh secara parsial variabel pemahaman peraturan $\left(\mathrm{X}_{1}\right)$, kesadaran wajib pajak $\left(\mathrm{X}_{2}\right)$, sanksi perpajakan $\left(\mathrm{X}_{3}\right)$ berpengaruh terhadap variabel kepatuhan wajib pajak (Y) berikut hasil dari uji t:

\begin{tabular}{|c|c|c|c|c|c|c|c|}
\hline \multicolumn{8}{|c|}{ Coefficients $^{\mathrm{a}}$} \\
\hline \multirow{2}{*}{ Model } & \multicolumn{2}{|c|}{$\begin{array}{l}\text { Unstandardized } \\
\text { Coefficients }\end{array}$} & \multirow{2}{*}{\begin{tabular}{|c|}
$\begin{array}{c}\text { Standardized } \\
\text { Coefficients }\end{array}$ \\
Beta \\
\end{tabular}} & \multirow{2}{*}{$\mathrm{t}$} & \multirow{2}{*}{ Sig. } & \multicolumn{2}{|c|}{ Collinearity Statistics } \\
\hline & B & Std. Error & & & & Tolerance & VIF \\
\hline (Constant) &, 530 & 1,109 & & ,478 & ,634 & & \\
\hline Pemahaman &,- 138 &, 100 &,- 150 & $-1,377$ &, 173 & ,947 & 1,056 \\
\hline Kesadaran & 623 &, 152 & ,448 & 4,106 &, 000 & ,946 & 1,057 \\
\hline Sanksi & ,424 & ,191 & 237 & 2,217 & 030 & ,987 & 1,013 \\
\hline
\end{tabular}

a. Dependent Variable: Kepatuhan

Dalam penelitian ini hasil pengujian hipotesis $1\left(\mathrm{H}_{1}\right)$ menunjukan bahwa pemahaman peraturan tidak berpengaruh signifikan terhadap kepatuhan wajib pajak, hal ini dapat dilihat pada tingkat signifikan 0,173 lebih besar dari 0,05, sehingga $\mathrm{H}_{1}$ ditolak. Hal ini dikarenakan peraturan-peraturan pajak yang terus diperbaharui sehingga menyebabkan kurangnya pemahaman wajib pajak, terutama perubahan tarif pajak yang berlaku saat ini sehingga wajib pajak paham atau tidaknya terhadap peraturan yang berubah-ubah tidak mempengaruhi kesadaran wajib pajak dalam melakukan pembayaran pajak Pph 21. .

Dalam penelitian ini hasil pengujian hipotesis $2\left(\mathrm{H}_{2}\right)$ menunjukan bahwa kesadaran wajib pajak berpengaruh terhadap kepatuhan wajib pajak, hal ini dapat dilihat 
dari tingkat signifikan 0,000 lebih kecil dari 0,05. Wajib pajak sadar bahwa membayar pajak untuk kepentingan negara, merupakan bentuk partisipasi dalam menunjang pembangunan negara, untuk itu pemerintah perlu terus melakukan sosialisasi untuk membangkitakan kesadaran dalam melakukan kewajibannya dalam melakukan pembayaran ataupun pelaporan perpajakan.

Dalam penelitian ini hasil pengujian hipotesis $3\left(\mathrm{H}_{3}\right)$ menunjukan bahwa sanksi perpajakan berpengaruh signifikan terhadap kepatuhan wajib pajak, hal ini dapat dilihat dari tingkat signifikan 0,030 lebih kecil dari 0,05. Sanksi sebagai upaya pemerintah agar wajib pajak tidak akan melalaikan kewajiban perpajakannya, karena dengan adanya sanksi akan memberi efek jera dan kepatuhan wajib pajak semakin meningkat.

\section{SIMPULAN DA SARAN}

\section{Simpulan}

Berdasarkan hasil pengujian hipotesis terhadap kuisioner yang terkumpul, dapat disimpulkan bahwa faktor pemahaman tidak berpengaruh signifikan terhadap kepatuhan wajib pajak, hal ini dapat dilihat pada tingkat signifikan 0,173 lebih besar dari 0,05, sehingga $\mathrm{H}_{1}$ ditolak dan $\mathrm{H}_{0}$ diterima. Sedangkan kesadaran menunjukan berpengaruh positif terhadap kepatuhan Wajib Pajak, hal ini dapat dilihat dari tingkat signifikan 0,000 lebih kecil dari 0,05. Sehingga $\mathrm{H}_{0}$ ditolak dan $\mathrm{H}_{2}$ diterima. Untuk sanksi perpajakan menunjukan berpengaruh positif terhadap kepatuhan Wajib Pajak hal ini dapat dilihat dari tingkat sanksi perpajakan mempunyai tingkat signifikansi sebesar 0,030 lebih kecil dari 0,05. Sehingga $\mathrm{H}_{0}$ ditolak dan $\mathrm{H}_{3}$ diterima.

\section{Saran}

Bagi Direktorat Jenderal Pajak (DJP) tetap melakukan berbagai penyuluhanpenyuluhan dan melakukan pemberian penghargaan kembali kepada distributor yang patuh terhadap kewajiban pajaknya. Bagi Wajib Pajak Pribadi yang berprofesi sebagai MLM seharusnya tetap aktif mengikuti sosialisasi yang diadakan oleh DJP. Walaupun penghasilan berupa bonus yang diperoleh, telah dikenakan Pajak Penghasilan Pasal 21 ( $\mathrm{PPh}$ 21) yang dipungut langsung oleh perusahaan MLM, namun yang bersangkutan wajib melaporkannya dalam SPT Tahunan. Bagi peneliti selanjutnya perlunya menambahkan variabel-variabel independen yang berpengaruh terhadap kepatuhan wajib pajak. Selain pemahaman, kesadaran, dan sanksi pajak. Seperti pelayanan fiskus, kemanfaatan NPWP, kebijakan tarif pajak atau persepsi keadilan pajak. Karena penelitian ini hanya berfokus pada wajib pajak pribadi yang berprofesi sebagai Multi Level Marketing di wilayah Surabaya. Bagi peneliti selanjutnya perlu menambah jumlah sampel dan memperluas objek penelitian profesi-profesi yang lain. 


\section{DAFTAR PUSTAKA}

Mardiasmo. (2011). Perpajakan (Edisi Revisi 2011). Yogyakarta : ANDI

MLM Leaders. (2007) The Secret Book of MLM. Surabaya: Menuju Insan Cemerlang. Permenkeu no, 101 tahun 2016 tentang Penyesuaian Besarnya Penghasilan Tidak Kena Pajak

Rahayu, S.K. (2010). Perpajakan Indonesia: Konsep dan Aspek Formal (Edisi Pertama). Yogyakarta: Graha Ilmu.

Siahaan, M.P. (2010). Hukum Pajak Elementer Konsep Dasar Perpajakan Indonesia. Yogyakarta : Graha Ilmu.

Soemitro, Rochmat. (1988). Pajak dan Pembangunan. Bandung: PT Eresco.

Undang-Undang Republik Indonesia No.28 tahun 2007 tentang perubahan ketiga atas undang-undang nomor 6 tahun 1983 tentang ketentuan umum dan tata cara perpajakan

www.liputan6.,com

www.m.tempo.co

www. media_indonesia.com 